\title{
A LIÇÃO DE HERÁCLITO
}

Maria Carolina Alves dos SANTOS*

RESUMO: Heráclito é conhecido na história do pensamento filosófico como o propositor da doutrina do mobilismo universal. O "tudo flui, nada permanece", asserção pela qual é comumente sintetizada, integra o cerne da Metafisica: suscita em Platão a não menos conhecida Teoria das Formas, que acabará por tornar-se o pensamento diretor da filosofia do Ocidente. Para melhor compreender essas ressonâncias, desenvolveremos algumas consideraçōes sobre a essência do devir heraclítico.

UNITERMOS: Heráclito; lógos; devir, enigma, harmonia dos contrários; Um e Múltiplo; fogo; Platão.

..." e de todas as coisas Um e de Um todas as coisas". (5, fr. 10)

A filosofia, sob a singular luminosidade de seu momento inaugural, manifesta desde logo múltiplas tentativas de enunciação de um princípio primeiro, único, elucidativo da ordem vigente no universo. Os primeiros pensadores, imersos ainda no mistério, atônitos, buscam a postura original, capaz de gerar esse novo dizer: especulando "sobre a natureza"; visam ao que nela é essencial e permanente. Heráclito é um deles.

Embora conhecido, na tradição filosófica, como "o pensador da mudança", o filósofo de Éfeso crê-e essa é a hipótese que procuraremos verificar aqui-na existência de algo primordial e unitário que persiste e explica a contínua transitoriedade manifestada pelas coisas da experiência. Este algo jamais poderia ser identificado ao absolutamente imóvel porque, para o grego, physis significa princípio ou fonte originária de onde incessantemente brota tudo o que é; e, nesse perpétuo desdobramento, torna observável não só o que por seu intermédio vem a ser como também a profunda dinamicidade que a caracteriza.

* Departamento de Filosofia da Faculdade de Filosofia e Ciências - UNESP - 17500 - Marília -SP. 
Aliando ao sopro místico-poético que anima os grandes iniciados um formidável esforço de compreensão racional do caráter próprio à phýsis, Heráclito compõe um livro. À semelhança do oráculo de Delfos, cujas ambíguas e curtas sentenças "nada mostram nem ocultam, apenas indicam", vaticina. Propositadamente escrito num estilo aforístico, hermético, enigmático, seu livro está destinado a causar perplexidade, a incitar a reflexão.

Hoje, em razão do estado fragmentário que a obra do filósofo chegou até nós, não nos é possível apreender plenamente o significado de sua intuição fundamental. A força contida em seu gesto inaugural, entretanto, é de tal ordem que continua através dos séculos, despertando a admiração, impulsionando a sempre novas tentativas de decifração, das miríades de sentidos que ele contém.

\section{O PROPOSITOR DE ENIGMAS}

"O senhor, de quem é o oráculo em Delfos, nem diz nem oculta, mas dá sinais."

O enigma, comseu caráter perturbador e ambíguo, ocupa um lugar central nas sentenças de Heráclito. A presença concomitante, em cada uma delas, de múltiplos sentidos em íntima contradição é sinal inequívoco das prof undas dimensões do "seu" lógos. Postado num domínio privilegiado, apanágio de sábios, porta-voz da divindade, nada esconde e também nada mostra: lança desafios. A palavra ambígua desperta a admiração, suscita do espírito a atividade que lhe é essencial, a decifração. Por isso mesmo, a palavra de Heráclito é extremamente significativa (aínos).

Para os gregos de um modo geral, o enigma (aínigma) é uma manifestação do divino, reveladora da distância existente entre a esfera humana e a não-humana, entre a região das aparências e a do invisível e eterno. Sua formulação, observa G. Colli, é sempre acompanhada de uma forte carga de hostilidade com relação ao mundo humano (2, p.43). O mito tebano da Esfinge, um desafio mortal imposto aos homens, ilustra a malevolência atribuída aos deuses. Face a ela, o recurso para preservar a vida (e salvar a cidade) é a sabedoria: "decifra-me ou ...". Vencer o desafio é decisivo para o sábio. Não deve ser imbatível no domínio das coisas do espírito aquele que aí busca notabilizar-se?

O enigma, em virtude de sua matriz religiosa, confere a quem o utiliza um caráter de iniciado. Elegê-lo como forma de expressão (ainittomai) significa ter familiaridade com a esfera mística, denota capacidade de transcender o domínio sensível. Às lendárias figuras que povoam os primórdios da civilização grega, videntes, adivinhos, poetas, atribui-se essa espécie de extra-sentido que lhes permitiria ascender à região do invisível. Revelam em seus vaticínios um saber de duplo aspecto: de mistério religioso e de doutrina de sabedoria (12, p.305).

A linguagem filosófica própria às especulações dos primeiros pensadores é ainda marcada por essa duplicidade. O lógos que expressa o formidável esforço de decif ração da physis, apesar de original guarda ainda um fundo religioso: "tudo é pleno de deuses", 
afirmava Tales. Pitágoras, fundador de uma ordem religiosa, pelo teor de suas doutrinas, é considerado um homem divino; Parmênides utiliza-se do vocabulário religioso das seitas e confrarias para exprimir suas reflexões em torno do ser; Empédocles, qual um gênio inspirado, ao apresentar suas idéias, profetiza.

Heráclito comporta-se também como um inspirado pelos deuses (éntheos). Invoca de forma enigmática o oráculo de Delfos. E Apolo é o grande profeta de quem recebem o dom todos os inspirados: torna clarividente e faz conhecer as coisas ocultas, garante a veracidade das sentenças proferidas. As de Heráclito não resultaram do mero cápricho ou de suas opiniões particulares e sim da força divina. "Não de mim mas do Lógos (fr. 50). Tal como o deus que o inspira (Apolo ama a solidão e o distanciamento), o filósofo mantém-se quase que inacessível. O estilo aforístico é sinal de hostilidade ao comum dos mortais? "Os homens não sabem ouvir nem falar, assemelham-se a surdos" (fr. 19, 34). É sinal da intenção de falar a um pequeno grupo de iniciados? "Os homens não compreendem nem antes de ouvi-lo nem ao ouvi-lo pela primeira vez" (fr.1). Investido do poder espiritual de Apolo, profere verdades eternas?

Nos fragmentos, em lugar de destacar sua pessoa - os oráculos do deus nunca iniciam suas profecias com "eu sou"-, Heráclito manifesta-se sobre o ser do universo. "Não de mim..." Ao construí-los ṇa terceira pessoa ("eles não sabem falar" (fr.19), "eles não compreendem" (fr.21), ou usando o genérico "homem" (fr. 26, 87, 119), ou "os muitos" (fr. $2,29,104)$, elude a própria identidade $(1, p .11)$. Como o deus que encarna, recusa o que é demasiado próximo, busca conhecer a Ordem, a Lei do Mundo. E o que enunciou? "Tendo ouvido do Lógos é sábio homologar que Tudo é Um."

Instaurada a separação entre aquele que diz e aquilo que será dito, numa sentença concisa, Heráclito circunscreve-aphorizo significa literalmente separar, delimitar, definir-a abrangência desse Lógos que fala através dele: reúne (légein) tudo. $\mathrm{Na}$ interpretação de Heidegger, o lógos de Heráclito opõe-se à dispersão, à dissipação e significa reunião. $\mathrm{Na}$ cultura grega, a fala (légein) já sugere essa idéia: "o que é o Lógos encontramos em légein que significa 'dizer', 'falar'... e também 'estender, deitar diante'" (4, p. 266, 251-5). Heidegger entende légein como o que deixa as coisas reunidas e estendidas diante dele, abrigadas na não-ocultação: o Lógos leva ao que aparece, ao que se produz e se estende diante de nós a se mostrar... Um semelhante légein é ómologein (falar de acordo com), afirma (4, p. 260).

Desvendar esse "tudo que é Um", contido no aforisma proposto - e assim compreender a lição de Heráclito - é tentar enfrentar um dos mais sibilantes enigmas que "o Obscuro" lançou diante de nós. É preciso, para tanto, transpor a enorme distância que nos separa (nós, neófitos, que o ouvimos) do Lógos que é dito e tentar pôr-se de acordo (ómologein) com ele.

No afã de decifrá-lo em seu original e pleno sentido, tem-se atribuído à palavra lógos, desde a Antigüidade, uma infinidade de significações. Norma do mundo, razão, relação, lei do devir, definição, enunciado, narrativa, reunião, devir (essas duas últimas 
correspondem às exegeses de Heidegger) são algumas delas. G. Legrand propõe Saber, no sentido global de "conhecimento discursivo", compreendido como resultante de um discurso especulativo e também no sentido de "possibilidade" deste conhecimento, enquanto há no kósmos um "saber" constituinte que o filósofo apreende, deixando-se penetrar por ele $(7$, p. 72$)$.

Nessa perspectiva, aquele que ouvir efetivamente, deixando-se penetrar pelo Saber, falará de acordo com ele. Como Heráclito, descartará o eu para abrigar-se no Lógos. Ou, conforme Heidegger, é nesse légein no sentido de ómologeinn, que o verdadeiro ouvir desdobra seu ser. E se o verdadeiro ouvir é como ómologeĩn, produz-se então uma boa disposição (sóphon) e o légein mortal se curva ao que lhe convém, o Lógos (p.263). Revelará (cxpandindo) um saber especial que tudo reúne e ordena. Ao discorrer em compasso com cle (de acordo com seu fluxo) exercerá um saber que reúne em si coisas contraditórias: "hén pánta" (tudo é Um). É sábio afirmar que "Tudo é Um", saber que esse Um reúne tudo e, no entanto, não significa indeterminação, perda de identidade, confusão. Enquanto conhecimento discursivo, esse Saber distingue cada coisa, segundo sua natureza, preserva assim sua singularidade, coloca em presença opostos como "dia e noite, inverno e verão, gucrra e paz, vigília e sono". O Saber desvela a diversidade constituinte do universo: o Um cm scuâmagoé múltiplo, o Ser é essencialmente Devir.Ei-nos diante de um terrível enigma.

\section{O MOBILISMO UNIVERSAL}

A obra de Heráclito tem por nome "Da natureza". O Lógos, que através dela a manifesta, fala de uma Ordem inexorável, Movimento constituído de tensões contrárias. Depositada no templo erigido em Éfeso, à Ártemis, irmã gêmea de Apolo, mantém misteriosa inacessibilidade, à semelhança dessas divindades.

O distanciamento significa, de acordo com a simbologia mítica, na índole masculina, liberdade espiritual, e na feminina, espelha a livre existência na natureza $(10$, p. 107). Caçando e dançando pelas pradarias, montanhas e selvas, Ártemis simboliza a serena separação, a solidão enigmática, a pureza inocente $(9$, p.50, 65). Seu maior prazer, como também o de Apolo, consiste no manejo, do arco e da lira. $\mathrm{O}$ arco curvado sobre a lira, a tensão da madeira em um sentido e a corda em outro, contém um profundo significado no saber que o Oráculo faz ecoar: unidade entre divergentes.

"Do arco o nome é vida, a obra é morte" (fr. 48). A phýsis é majestosamente constituída de uma infinidade de elementos díspares em perpétua movimentação (unindo-se e separando-se), que nascem, florescem e perecem. Inspiradó nos harmoniosos sons que brotam da lira de Apolo - a música do mais sublime dos deuses identifica-se à melodia do universo-, o Lógos canta a ordem que subjaz a essa extraordinária composição de fenômenos: a vida se resume no perene combate entre forças opostas. "Todas (as coisas) vêm a ser segundo a discórdia e a necessidade" (fr. 80). A obra da vida é a morte e entre esses contrários persiste a irrecusável ligação, o inexorável vai-vem estabelecido pela convergência inerente à essência do arco. 


\subsection{O tema da luta harmônica entre tensões contrárias}

"... o contrário é convergente e dos divergentes nasce a mais bela harmonia, e tudo segundo a discórdia". (fr. 8)

Os princípios antinômicos, que o Lógos reúne em seu dizer, estabelecem entre si um bem ordenado jogo de convergências, em virtude do qual cada um afirma sua natureza, assegurando assim a própria identidade e ainda a identidade do todo. $O$ todo e o não-todo, o convergente e o divergente, o consoante e o dissonante, se isolados, seriam abstrações sem verdade, incompreensíveis: apenas existem, um em função do outro, pertencentes que são a uma mesma (e única) totalidade. Esta, da mesma maneira, sem a permanente presença dos contrários, jamais seria o que em sua essência é.

Assim, no "hèn pánta", sinteticamente inserido nessa fórmula paradoxal "de todas as coisas o Um e do Um todas as coisas", está implícito também o Múltiplo. Melhor dizendo, é a unidade mesma, enquanto conceito, que participa do jogo de forças contrárias reinante no universo. Por isso se diz que o Um é Múltiplo, que a unidade é não-unidade, embora em nenhum momento deixe de ser isso que ela é. Os divergentes convergem e divergem eternamente, são coisas diferentes, mas ao mesmo tempo são aspectos de uma mesma coisa. Segundo Nietzsche, todas essas leis, qualidades das coisas, nascimentos, destruições, às quais se refere Heráclito, são manisfestação constante do único $(8$, p.45).

Do conflito de contrários existente no centro de todas as coisas e que preside a vida do universo resulta a mais bela harmonia. Tudo tem origem na luta, na oposição essencial entre a unidade e a diversidade, e o ritmo cadenciado é próprio dela. Das tensões opostas entre o arco e a lira de Apolo nasce a música unificadora que estabelece o princípio da Harmonia. Se "harmonia" significa reunião, acordo, ordem, o Lógos que "distingue cada coisa explicando como se comporta" (fr. 1) e homologa que tudo é Um, não é essencialmente harmonia? Por essa razão, observa Nietzsche, o devir do qual fala Heráclito em nada se assemelha ao de Anaximandro, cujas transformações se processam sem regra ou ordem $(8, \mathrm{p} .45)$.

Esse Lógos de quem o pensador "obscuro" é porta-voz teria surgido na História com incomparável brilho. Trata-se, segundo Hegel, da idéia filosófica em sua forma especulativa. Com Heráclito surge a luz do pensamento, o primeiro discurso da razão (3, p. 154). Em relação a seus predecessores isso significa o momento da total concretização da consciência. $\mathrm{Na}$ medida em que propõe a identidade dos contrários, reunidos no conceito superior do devir, concretiza-se, pela primeira vez na história, a totalidade ( $3, \mathrm{p}$. 153). Seu pensamento representa um progresso também porque supera a oposição do subjetivo ao objetivo, ao passar da linguagem da representação para a linguagem do conceito. Em suma, no dizer de Hegel, são esses dois aspectos essenciais do pensamento de Heráclito - devir e enquanto Lógos - que constituem a primeira totalidade especulativa.

Sob essa perspectiva, a paradoxal afirmação "Tudo é Um" significa o conjunto das coisas múltiplas (ele é Um na medida em que é múltiplo) e não o Um-único (6, p. 240-1). Esse 
Um que é Tudo, é movimento, multiplicidade, contradiz radicalmente o Um concebido por Parmênides como absoluto, imóvel, pontual. A pluralidade, considerada ilusão dos sentidos pelo pensador de Eléia é, para Heráclito, a forma fenomenal do único, observou Nietzsche: "o mundo da pluralidade é o mundo do único" (8, p. 45-6). Dizendo de outra maneira, se para Parmênides a verdade é o ser, a intuição de Heráclito pode ser resumida na seguinte fórmula: a verdade do ser é o devir. E a transposição do devir para o Ser assim efetuada não representa uma mera substituição do ser de Parmênides pelo devir. A função atribuída ao ser pelo eleata é exercida pelo devir, o ser apenas assegura a própria identidade através do devir.

Essa proposição de Heráclito, inspirada pelo deus, ressoa através do tempo e contra eco no pensamento de Platão. No Sofista, após decidir-se pelo "parricídio", o tile $f_{0}$ retoma o tema heraclitiano da luta e harmonia dos contrários: o não-ser é, e o ser não , afirma. O não-ser se define não como contrário do ser mas como outro ser, conferindo assim um caráter positivo à negação. "Quantas vezes os outros são, tantas vezes o ser não é" (257a). Conseqüentemente, Platão admite que há no movimento um ser do não-ser (256d), que o ser e o não-ser penetram através de tudo e se interpenetram mutuamente (258b). Utilizando-se do método de divisão dicotômica, Platão investiga, naquele diálogo, a multiplicidade de aspectos do sofista. Na busca de uma visão de conjunto, pesquisa um campo mais vasto, supera antigas aporias e acaba por alcançar a forma unificadora. Vê o ser como relação, admite que é no dinamismo característico à toda relação - à semelhança da tensão entre os opostos estabelecida pelo Lógos heraclitiano - que ele se define. Ser e não-ser são forças opostas inseparáveis. Assim como o Um é sempre Múltiplo, segundo Heráclito, ser e não-ser coexistem no pensamento platônico: o ser é movimento e não-movimento, ainda que não o seja simultaneamente.

Com a concepção do ser relacional, Platão revela ter ouvido (e homologado) a doutrina da luta harmônica entre os contrários e superado, na última fase de seu pensamento, "o dogmatismo ontológico que a tradição lhe atribui com tanta insistência" (11, p. 41). O princípio veiculado por Heráclito, embora seja intensamente claro, será sempre obscuro para aqueles que mantêm separados o ser e o não-ser.

\subsection{O Elemento Primordial}

"Pois todas (as coisas) o fogo sobrevindo discernirá e empolgará". (fr. 66)

O devir entre os opostos, enquanto ritmo harmônico, eterno, universal, é uma verdade que pode ser apreendida, em certa medida, pela observação da mudança que predomina na região do sensível. Assim, o rio com suas águas em perpétuo fluxo e a sucessão de sóis continuamente novos (fr. 91, 49a, 6). E, para além da instância visível, num domínio que escapa à percepção, oculto, insondável, vigora uma harmonia infinitamente superior à outra (fr. 54). É ela quem condiciona e detém a chave das aparições sensíveis, do contínuo trânsito de um estado oposto a outro, enfim, da vida mesma do universo. Constituída 
essencialmente do tecido de contrários em contínua mudança, possui como cerne o princípio primeiro de tudo que há: o fogo.

A natureza do enigma é tão contraditória quanto a trama do objeto cuja essência ele procura sugerir, o real. Por tentar ser veículo de expressão da harmonia superior que é oculta, o enigma é em si mesmo obscuro. O Lógos que o profere, visando torná-lo menos impenetrável, ilumina-o com um clarão avassalador eternamente vivo. $\mathrm{O}$ fogo, sendo esclarecimento contínuo, é o elemento imprescindível à decifração do mistério da physis. Diante de um enigmático par de contrários, que outra solução pode haver senão a unidade?

Apesar das sucessivas metamorfoses desencadeadas nos ciclos da matéria pelo incessante devir, o fogo é o elemento que subsiste e permanece eternamente idêntico (fr. 30). É o arkhé (princípio) qual tudo o mais procede. Sendo ele mesmo não engendrado, existe desde sempre: "o mundo (kósmos) o mesmo de todos os seres, nenhum deus, nenhum homem o fez mas era, é e será um fogo sempre vivo, acendendo-se em medidas e apagando-se em medidas" (fr. 30). A substância ígnea, identificada pelo Lógos ao próprio kósmos, opera constantes transformações nos elementos centrais da natureza, água, terra, ar, com medida e funciona como receptáculo delas.

Abrigo de princípios contrários, o fogo é essencialmente contradição: carência e saciedade são o par de opostos que explicam sua ação no universo (fr. 65). Animado pela carência, cresce e se mantém enquanto houver o que devorar. Por sua natural indigência, destrói as diferenças entre as coisas, ao mesmo tempo em que, sobrevindo, opera distinções, através de suas correlativas mutações, caracterizando cada uma delas: anula particularidades e também "discerne e julga" (fr. 66). Segundo Platão, o fogo heraclítico é o princípio sutil inteligível que, insinuando-se por toda parte, governa o universo (Crat. 413b).

Em última instância, o fogo heraclítico consubstancia em si mesmo todos esses elementos que o Lógos vem reunindo para constituir o Saber, e revelá-lo diante de nós, "fazendo-se ver em luz". "O deus é dia-noite, inverno-verão, guerra-paz, saciedade-fome, mas se alterna como o fogo, quando se mistura a incensos e se domina segundo o gosto de cada" (fr. 67). Sendo por natureza carência e saciedade, o fogo se conflagra alastrando-se através de tudo, mistura-se ao deus que julga e vigia, identifica-se à harmonia que reúne em si as convergências e divergências, ao combate que é de todas as coisas o pai, unifica-se ao arco que é vida: ele é, essencialmente, o Um do qual todas as coisas nascem. Não será também a consubstanciação desse enigmático Lógos que ouvimos e tentamos decifrar?

\section{CONCLUSÃO}

A verdade que o comum dos homens parece não compreender, habituados como estão a ver os componentes do real separadamente, é como uma única coisa pode conter em si determinações opostas sem deixar de constituir uma unidade perfeita. A maioria deles, incrédulos acerca de tudo que ultrapassa a experiência sensível, tende a desprezar o Um 
e se atém à multiplicidade, que é aparente. Mas não Heráclito. Ouviu do Lógos os sinais que lhe deram acesso à inteligência do real. Conseguiu ver com clareza (épisóphos) a harmoniosa ligação dos termos antitéticos, com os quais ele é tecido. Vigilante, chegou a perceber o fogo, princípio primeiro de todas as coisas, como a consubstanciação desse Lógos que se estende diante dele e revela sua essência: é esclarecimento contínuo. Por isso, sua obra significa um momento singular, fundamental e insubstituível no esforço que o espírito humano vem fazendo, através dos séculos, por compreender o real. Como o arco, cujo nome é vida, ele vem garantindo a ligação entre a esfera humana e a divina, assegurando a comunicação entre o domínio do visível e do invisível, indicando com sentenças delirantes, a via que conduz ao Saber.

Tendo decifrado os sinais emitidos peloLógos, Heráclito apreendeu a lei divina, eterna, que rege e unifica o real. $\mathrm{O}$ devir é uma ordem que, por ser permanente, perpétua, jamais deixa de ser o que é em sua essência: Ordem. E compreendeu que o próprio Lógos, que atribui a essa lei eterna a função reguladora e ordenadora, é, ele mesmo, devir. O contínuo fluxo é característica fundamental do Lógos.

Teria sido hostil aos neófitos, como nós, se tivesse silenciado sobre isso. Valendo-se, porém, dessa misteriosa arte da palavra, o enigma, teceu fragmentos com os mesmos fios que o Lógos tece o real. Numa linguagem ambígua, discerne e julga tal como o fogo: desvenda o jogo secreto e incessante dos contrários, diferencia as coisas subsumidas por eles, atribui-lhes um nome. E é esse nome, sob o qual reúne coisas múltiplas e dispersas, único, que permanece. O nome dado a cada ser é e não é isso que exprime, paradoxalmente, como a própria realidade a que se refere, mas é sempre o mesmo: o rio, com suas águas sempre novas, enquanto rio (conceito) permanece.

Em oposição à indiferenciação inicial reinante nos primórdios do pensamento filosófico, Heráclito procurou fazer justiça à natureza de cada coisa, estabelecendo diferenças. Tal como o sol de quem nada se pode esconder. O Lógos, que através do filósofo legisla, nomeando tudo, incide também, como chama sempre viva que é, sobre as interpretações tradicionais que dele se faz. Em sua voracidade insaciável, alimenta-se delas e permanece: devir e permanência, um par de contrários, cuja convergência possibilita a perenidade do devir e do próprio Lógos, que o pôs como essência do real. Pelo trânsito incessante entre esses contrários, torna-se possível discernir cada um deles enquanto nome separado da coisa a que se refere; e ainda julgar que o Lógos de Heráclito é não só devir: ele quer (e não quer) ser entendido como permanência. Pois se assim não fosse, o próprio filósofoteria chegado à impossibilidade de transmitir-nos a magistrallição que recebeu do Lógos. 
SANTOS, M.C.A. dos-The Heraclitus'lesson. Trans/Form/Ação, São Paulo, 13: 1-9, 1990.

ABSTRACT: Heraclitus is known in the history of thought, for his doctrine of universal mobilism. The enigmatic proposition "everythingflows nothing remains unchanged" lies at the core of Western Metaphysics: it inspired Plato's Theory Of the Two Worlds-which puts forward a radical separation between that which moves and which doesn't-and also the platonic view of the last Dialogues, which includes motion among the attributes of being. In view of these influences and in order to understand well the genesis of Western Phylosophy, it seems to us that it would be important to reflect a bit more on the essence of Heraclitus' becoming.

KEY-WORDS: Heraclitus; becoming; enigma; harmony of the opposites; fire; the one and the multiple; logos; Plato.

\section{REFERÊNCIAS BIBLIOGRÁFICAS}

1. BOLLACK, J. Héraclite ou la séparation. Paris, Minuit, 1972.

2. COLLI, G. El nascimiento de la filosofia. Barcelona, Tusquets, 1977.

3. HEGEL, G.W.F. Leçons sur l'histoire de la philosophie. Paris, J. Vrin, 1971.

4. HEIDEGGER, M. Logos, in Essais et Conférences. Paris, Gallimard, 1954.

5. HERÁCLITO. Heráclito. São Paulo, Abril Cultural, 1973. (Os pensadores)

6. KOJÈVE, A. Essai d'une histoire raisonnée de la philoso phie paienne. Paris, Gallimard, 1968.

7. LEGRAND, G. La pensée des présocratiques. Paris, Bordas, 1970.

8. NIETZSCHE, F. La naissance de la philosophie à l'époque de la Tragédie Grecque. Paris, Gallimard, 1938:

9. OTTO, W. Los dioses de la Grecia. Buenos Aires, Ed. Universitaria, 1973.

10. OTTO, W. Teofania. Buenos Aires, Ed. Universitaria, 1978.

11. PACCI, E. La evolución de la dialéctica. Barcelona, Martinez Roca, 1971.

12. VERNANT, J.P. Mito e pensamento entre os gregos. São Paulo, Difusão Européia do Livro, 1973. 